\title{
Management of Advanced Medullary Thyroid Carcinoma with Vandetanib: Case Series
}

\author{
Luis F. Fierro-Maya ${ }^{1}$, Andrés Flórez $\mathbf{R}^{1,2^{*}}$, Angélica M. González-Clavijo ${ }^{1}$, Andrés A. Cuellar C.1, Mireya Tapiero G1 , Claudia Córdoba C ${ }^{3}$ \\ ${ }^{1}$ Endocrine oncology. National Cancer Institute. Bogotá DC, Colombia. \\ ${ }^{2}$ Endocrinology, Hospital de San Jose. Bogotá DC, Colombia.
}

${ }^{3}$ Radiologist. National Cancer Institute. Bogotá DC, Colombia.

*Corresponding Author: Andrés Flórez R, Endocrinology, Hospital de San Jose. Bogotá DC, Colombia.

Received date: February 15, 2021 ; Accepted date: March 11, 2021; Published date: March 15,2021

Citation: Luis F. F-Maya, A Flórez R, Angélica M. G-Clavijo, A A. Cuellar C, M Tapiero G, et al. (2021) Management of Advanced Medullary Thyroid Carcinoma with Vandetanib: Case Series J. Endo and Dis, 5(1); DOI:10.31579/2640-1045/103

Copyright: @ 2021 Andrés Flórez R, This is an open access article distributed under the Creative Commons Attribution License, which permits unrestricted use, distribution, and reproduction in any medium, provided the original work is properly cited.

\section{Abstract}

Objective: To describe the tumor response and adverse events in patients with advanced medullary thyroid carcinoma (MTC) treated with vandetanib at the National Cancer Institute in Bogotá, Colombia.

Materials and methods: Case series including five patients with advanced MTC treated with vandetanib from April 2011 to August 2018 and a minimum follow-up of 6 months.

Results: 5 patients met the inclusion criteria, including 3 women. The mean age was 49 years. A total of 4 patients underwent total thyroidectomy prior to starting vandetanib. The main indication for vandetanib was progression of liver metastasis (4 patients). Regarding treatment response, 3 patients presented stable disease, 1 patient showed partial response, and 1 had disease progression. The mean treatment duration was 16.5 months. Grade 3 or 4 adverse events were observed in three patients, 1 with diarrhea, 1 with hypertension, and 1 with rash. All symptoms improved with dose reduction or temporary suspension of vandetanib.

Conclusions: The management of advanced MTC with vandetanib allows for prolonged disease control (stable disease or partial response). Although adverse events are frequent, most are mild and severe cases are manageable.

Keywords: medullary thyroid cancer; vandetanib; tyrosine kinase inhibitors; safety; retmutation

\section{Introduction}

Medullary thyroid carcinoma (MTC) accounts for $1-2 \%$ of all types of thyroid cancer in the United States [1]. The disease can occur sporadically (75\%) or be inherited (25\%) [2] Germline mutations of the RET oncogene are identified in multiple endocrine neoplasia (MEN) $2 \mathrm{~A}$ or $2 \mathrm{~B}$ and familial MTC [3] and are characterized by different clinical presentations according to the variant type. Somatic mutations of this gene are found in $50 \%$ of sporadic MTCs [4]. RAS gene mutations have been described in $68-81 \%$ of the patients with MTC without mutations [5,6].

The treatment of choice for MTC is total thyroidectomy with central neck dissection and, depending on the case, lateral neck dissection [1]. Patients with MTC commonly present with extensive regional involvement or distant metastatic disease at diagnosis or during follow-up, which hinders achievement of cure with the initial surgical intervention [2]. The overall survival at 10 years in patients with metastatic disease is $40 \%$ [7]. The therapeutic options in cases of advanced MTC include palliative surgery, radiotherapy, locoregional therapies, and systemic treatment with tyrosine kinase inhibitors (TKIs) such as vandetanib [1].

In the current research, we present 5 patients with advanced MTC who required therapy with vandetanib and progressed with disease control (stable disease and partial response). We also report the adverse events (AEs) observed with therapy.

\section{Methods}

The study included patients with a diagnosis of MTC confirmed by the pathology service at the National Cancer Institute, with either hereditary or sporadic disease. Presence of advanced disease defined by the occurrence of distant metastases with progression in the previous year according to the Response Evaluation Criteria in Solid Tumors (RECIST) version 1.1 [8], who were managed with vandetanib and had a minimum follow-up period of 6 months after treatment start. A search of medical records was conducted between April 2011 (when the Food and Drug Administration [FDA] approved vandetanib) and August 2018.

Diagnostic images were obtained $0-3$ months before the start of vandetanib (pre-TKI) and every 3 months thereafter. The imaging tests included non-contrast chest computed tomography (CT), abdominal CT with contrast, or magnetic resonance imaging (MRI) with arterial-phase contrast enhancement, and additional studies according to specific involvement (e.g. spinal MRI). A single INC radiologist (CCC) reviewed the images to decrease interobserver variation. Tumor response was evaluated according to RECIST version 1.1 [8], disease control rate 
(DCR) was defined as the proportion of patients who show, complete response, partial response (PR) or stable disease (SD). Progression rate was considered as the time in weeks elapsed between the last diagnostic image showing stable disease and the image showing progression (preTKI). The time (in weeks) elapsed between the diagnosis of progression and the start of treatment was recorded.

Clinical and laboratory follow-up was carried out in the following time points: before treatment start, week 2 , month 1 and 3 , and every 3 months thereafter. Clinical follow-up was carried out by the coauthors of this paper. Treatment-related adverse events (AEs) assessed with the Common Terminology Criteria for Adverse Events (CTCAE ) version 5.0 [9], body weight, blood pressure, and findings from physical examination were recorded at each assessment. Body weight was measured with a Health o Meter professional scale ${ }^{\circledR}$ (Sunbeam Products, Boca Raton, Florida, USA) and recorded in kilograms $(\mathrm{kg})$. Blood pressure was measured with a blood pressure monitor (Vismo, Nihon Kohden, Tokyo, Japan) and recorded in $\mathrm{mmHg}$. Clinical laboratory tests and diagnostic images were performed at the INC. Laboratory tests requested prior to treatment start included TSH, creatinine, transaminases (AST and ALT), complete blood count (CBC), hepatitis B surface antigen, hepatitis $\mathrm{C}$ antibodies, calcium $(\mathrm{Ca})$, potassium $(\mathrm{K})$, magnesium $(\mathrm{Mg})$, and electrocardiogram (ECG). Complementary tests requested during follow-up included TSH, CBC, creatinine, AST, ALT, Ca, K, Mg, and ECG. Bazett's formula [10] was used to calculate the corrected QT interval (QTc), and the result was recorded in milliseconds (ms). All patients underwent a RET mutation analysis, and the presence or absence of the mutation and the type of mutation were documented.

\section{Results}

Of 10 patients identified, 5 were excluded due to a follow-up period shorter than the predetermined one or due to incomplete data for analysis. Of the 5 patients included, 3 were women. The mean age at diagnosis was 37 years. Only one case of germline RET mutation was identified in a patient with a diagnosis of pheochromocytoma and lichen cutaneous amyloidosis (Patient 4: c634r mutation). The characteristics of the patients in terms of staging, metastatic site, and relapse are described in Table 1. Prior to initiating the TKI, Patients 4 and 5 had chronic diarrhea, which was attributed to elevated serum calcitonin; however, the diarrhea failed to improve after treatment start, despite the reduction in calcitonin levels.

\begin{tabular}{|c|c|c|c|c|c|c|c|c|c|}
\hline \multicolumn{8}{|c|}{ Table 1: Characteristics of the patients treated with vandetanib } \\
\hline Patient & $\begin{array}{c}\text { Age } \\
\text { (years) }\end{array}$ & $\begin{array}{c}\text { Sex } \\
\text { (M or } \\
\text { F) }\end{array}$ & $\begin{array}{c}\text { Age at } \\
\text { diagnosis } \\
\text { (years) }\end{array}$ & $\begin{array}{c}\text { Year of } \\
\text { diagnosis }\end{array}$ & TNM & Stage & $\begin{array}{c}\text { RET } \\
\text { germline } \\
\text { mutation }\end{array}$ & $\begin{array}{c}\text { Locoregion } \\
\text { al } \\
\text { recurrence }\end{array}$ & $\begin{array}{c}\text { Distant metastases } \\
\text { (year) }\end{array}$ \\
\hline 1 & 31 & M & 27 & 2014 & TxNxM0 & I & No & Yes (2016) & H and P (2017) \\
\hline 2 & 49 & F & 34 & 2003 & T4aN1bM0 & IVa & No & $\begin{array}{c}\text { Yes (2006, } \\
\text { 2011) }\end{array}$ & $\begin{array}{c}\text { P (2006), } \\
\text { mediastinum }\end{array}$ \\
\hline 3 & 63 & M & 54 & 2009 & T3N1aM0 & III & No & Yes (2011) & P (2012), H (2016) \\
\hline 4 & 42 & F & 14 & 1990 & TxNxM0 & I & c634r & Yes (2012) & $\begin{array}{c}\text { H (2000), P (2006), } \\
\text { B (2008) }\end{array}$ \\
\hline 5 & 60 & F & 57 & 2015 & TxN1bM1 & IVc & No & $\begin{array}{c}\text { P, retroperitoneal } \\
\text { LN, paravertebral } \\
\text { mass (2014) }\end{array}$ \\
\hline
\end{tabular}

Table 2 presents the types of treatment received by the patients before the start of TKI and the indications for initiation of therapy. Vandetanib was started between 1 and 27 years after the diagnosis. Patient 4, who had the longest disease duration, received sorafenib for 8 months, 2 years before starting vandetanib, until progression was demonstrated. In all patients, the starting dose of vandetanib was $300 \mathrm{mg} /$ day; however, due to side effects, the dose was reduced to $200 \mathrm{mg} /$ day in 3 of 5 patients. The biochemical response (levels of calcitonin and carcinoembryonic antigen) was irregular and showed no correlation with the structural response.

\begin{tabular}{|c|c|c|c|c|c|c|c|c|c|c|}
\hline \multicolumn{11}{|c|}{ Table 2. Treatment } \\
\hline Patient & $\begin{array}{l}\text { Inittal local / } \\
\text { regional Sx }\end{array}$ & $\begin{array}{c}\text { No. Sx prior } \\
\text { to TKI }\end{array}$ & Radiotherapy & $\begin{array}{c}\text { Mx prior to } \\
\text { TKI }\end{array}$ & IAE & $\begin{array}{c}\text { TKI } \\
\text { indication }\end{array}$ & $\begin{array}{c}\text { Time from dx } \\
\text { to TKI start } \\
\text { (years) }\end{array}$ & $\begin{array}{c}\text { Time from } \\
\text { progression to } \\
\text { TKI start (Wks) }\end{array}$ & $\begin{array}{c}\text { Progression } \\
\text { rate (Wks) }\end{array}$ & $\begin{array}{l}\text { TKI final dose } \\
\text { (mglday) }\end{array}$ \\
\hline 1 & Yes & 4 & No & No & No & $\mathrm{HP}$ & 3 & 16 & 12 & 200 \\
\hline 2 & Yes & 2 & $\begin{array}{l}\text { Mediastinal } \\
(3000 \text { cGy) }\end{array}$ & No & № & $\begin{array}{l}\text { MP with } \\
\text { SVC } \\
\text { compressio } \\
n, H P \text {, and } \\
\text { RB lesion }\end{array}$ & 13 & 24 & 60 & 200 \\
\hline 3 & Yes & 2 & No & Yes (liver) & No & $\mathrm{HP}$ & 8 & 40 & 16 & 200 \\
\hline 4 & Yes & 2 & $\begin{array}{c}\text { TL spine ( } 3000 \\
\text { CGy) }\end{array}$ & No & Yes (liver) & $\mathrm{HP}$ & 27 & 20 & 52 & 300 \\
\hline 5 & No & None & No & No & № & $\begin{array}{l}\text { PP and } \\
\text { LNP }\end{array}$ & 1 & 16 & 20 & 300 \\
\hline
\end{tabular}


The mean treatment duration with vandetanib was 16.5 months (6 to 27 months). Patient 2 had the longest follow-up (27 months) and presented stable disease at the time of data collection for the present study, although it should be noted that the size of the lesions increased by $14 \%$ at month 24 compared with baseline. A total of 3 patients presented stable disease,
1 patient had partial response, and 1 had progression of liver lesions 12 months after beginning treatment. Table 3 shows the tumor response by patient. Figure 1 shows the abdominal MRI of Patient 1 , showing stable response at month 12 at the hepatic level. Figure 2 shows partial response at month 24 in Patient 5.

\begin{tabular}{|c|c|c|c|c|c|c|}
\hline \multicolumn{7}{|c|}{ Table 3:Tumor response with vandetanib (RECIST 1.1) } \\
\hline Patient & $\begin{array}{c}\text { Month 3 } \\
\text { response }\end{array}$ & $\begin{array}{c}\text { Month 6 } \\
\text { response }\end{array}$ & $\begin{array}{c}\text { Month 12 } \\
\text { response }\end{array}$ & $\begin{array}{c}\text { Month 18 } \\
\text { response }\end{array}$ & $\begin{array}{c}\text { Month 24 } \\
\text { response }\end{array}$ & $\begin{array}{c}\text { Best tumor } \\
\text { response }\end{array}$ \\
\hline 1 & Stable & Stable & Stable & Stable & Stable & Stable \\
\hline 2 & Stable & Stable & Stable & Stable & $\begin{array}{c}\text { Stable } \\
14 \% \text { growth }\end{array}$ & \\
\hline 3 & Stable & $\begin{array}{c}\text { Stable } \\
\text { decrease } \\
18 \%\end{array}$ & Progression & & & $\begin{array}{c}\text { Stable } \\
\text { Decrease 18\% } \\
\text { until month 12 }\end{array}$ \\
\hline 4 & Stable & Stable & Stable & Stable & & Stable \\
\hline 5 & $\begin{array}{c}\text { Partial } \\
\text { decrease } \\
30 \%\end{array}$ & Partial & Partial & Stable & & Partial \\
\hline
\end{tabular}

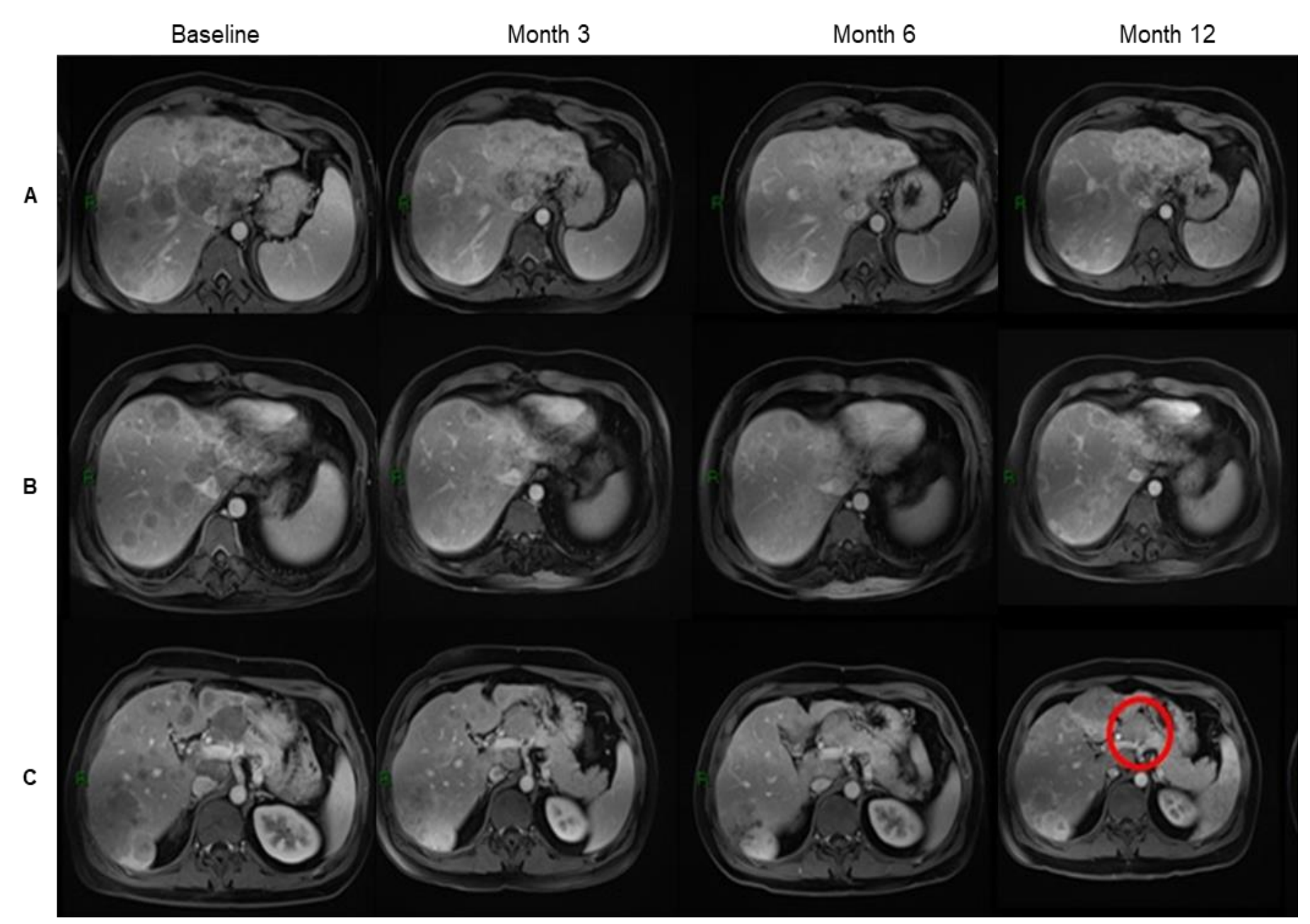

Figure 1 Abdominal T1-weighted gadolinium-enhanced MR image in chronological order A. Hepatic metastases left lobe. B. Hepatic metastases right lobe. C. Conglomerate nodal metastatic gastrohepatic ligament (red circle). Response stable (RECIST 1.1) 


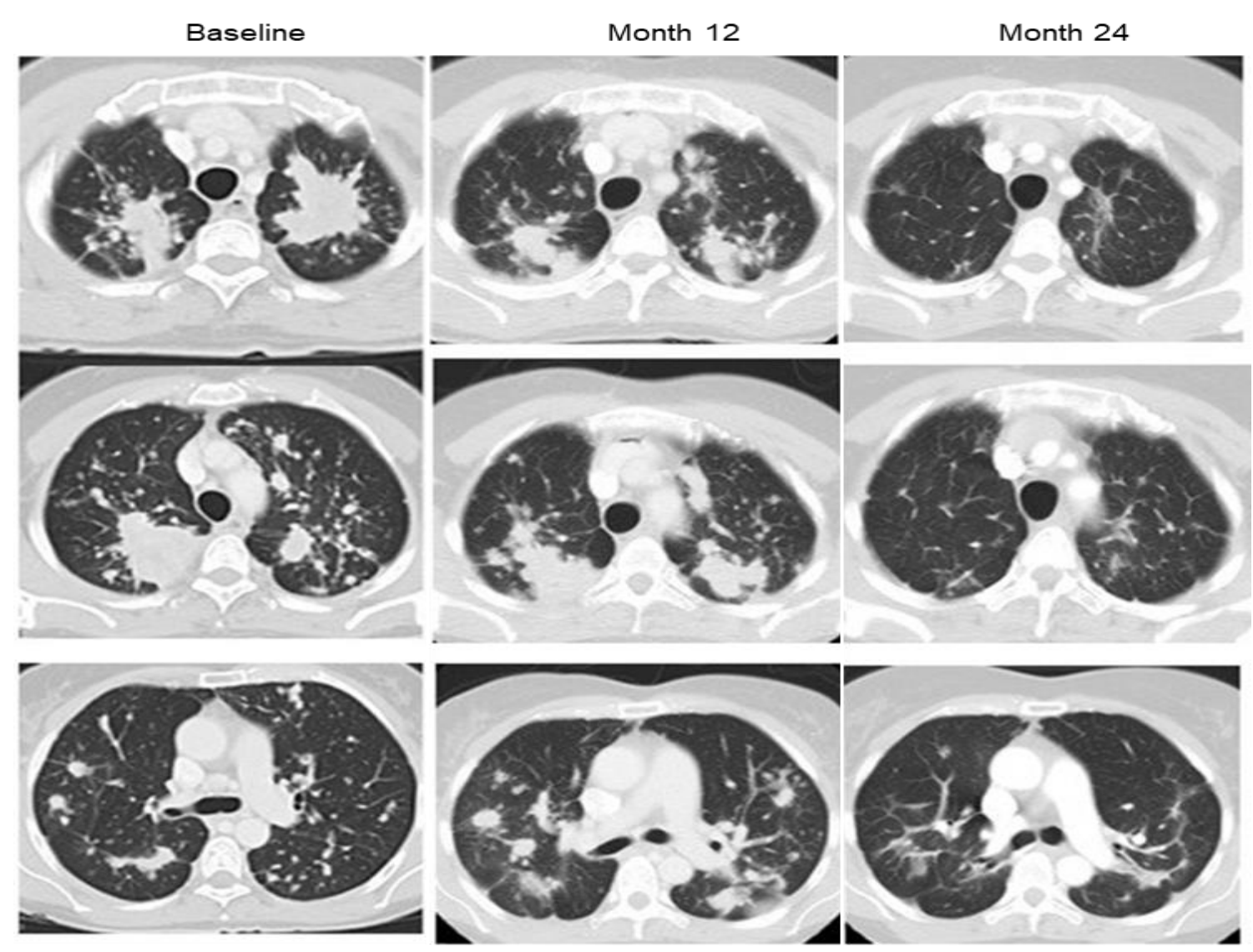

Figure 2. Axial thorax CT with contrast upper lobes. Masses and nodules with soft tissue density and metastasis are identified, with a partial response (RECIST 1.1) comparatively between baseline and month 12, the partial response is maintained until month 24, a decrease in the number and size of lesions is observed.

The most frequent AEs, mean time for emergence of AEs after TKI start, and mean duration of symptoms are shown in Table 4. Most AEs were grade 1 or 2 . The most frequent AEs observed in the first 8 weeks postTKI were diarrhea (2 patients), creatinine elevation ( 2 patients), and TSH elevation (4 patients). The most frequent dermatological symptoms were acne (patient 1), hand-and-foot syndrome and rash (patient 2), and photosensitivity (patients 3 and 4 ). Figure 3 shows the photosensitivity reaction presented by patient 3 . The patients with dermatological AEs received topical management recommended by a dermatologist. Grade 3 or 4 AEs included diarrhea (1 patient), hypertension (1 patient), and rash (1 patient). Patient 3 presented grade 3 diarrhea (10 to 15 episodes daily), which started 4 weeks post-TKI and resolved after a decrease in vandetanib dose. Patient 2 presented grade 3 hypertension at 2 weeks post-TKI, which was controlled with antihypertensive drugs and a reduction in TKI dose.

\begin{tabular}{|c|c|c|c|c|}
\hline \multicolumn{5}{|c|}{ Table 4: Adverse events } \\
\hline AE & Frequency all grades & Grade 3/4 & $\begin{array}{c}\text { Mean (wks) from } \\
\text { TKI start }^{1}\end{array}$ & $\begin{array}{c}\text { Mean duration } \\
\text { (wks) }^{2}\end{array}$ \\
\hline Diarrhea & $2 / 5(40 \%)$ & $1 / 5(20 \%)$ & 6 & 10 \\
\hline Hypertension & $2 / 5(40 \%)$ & $1 / 5(20 \%)$ & 10 & 20 \\
\hline Photosensitivity & $2 / 5(40 \%)$ & $0 / 5$ & 42 & 16 \\
\hline Rash & $1 / 5(20 \%)$ & $1 / 5(20 \%)$ & 8 & 82 \\
\hline Acne & $1 / 5(20 \%)$ & $0 / 5$ & 8 & 40 \\
\hline Hand-and-foot syndrome & $1 / 5(20 \%)$ & $0 / 5$ & 2 & 24 \\
\hline Headache & $1 / 5(20 \%)$ & $0 / 5$ & 8 & 22 \\
\hline Elevation transaminases & $1 / 5(20 \%)$ & $0 / 5$ & 8 & 8 \\
\hline Elevation creatinine & $2 / 5(40 \%)$ & $0 / 5$ & 2 & 6 \\
\hline Hypermagnesemia & $1 / 5(20 \%)$ & $0 / 5$ & 16 & 16 \\
\hline Hypercalcemia & $1 / 5(20 \%)$ & $0 / 5$ & 2 & 52 \\
\hline Hyperkalemia & $1 / 5(20 \%)$ & $0 / 5$ & & 28 \\
\hline
\end{tabular}




\begin{tabular}{|c|c|c|c|c|}
\hline Increase in TSH & $4 / 5(80 \%)$ & $0 / 5$ & 2 & 28 \\
\hline Prolonged QTc & $1 / 5(20 \%)$ & $0 / 5$ & 24 & 12 \\
\hline Abbreviations: AE: adverse event, wks: weeks, TKI: tyrosine kinase inhibitor. \\
\\
$\quad \begin{array}{r}{ }^{1} \text { Mean (in weeks) presentation of the AE after TKI start. } \\
2\end{array}$ \\
\hline
\end{tabular}

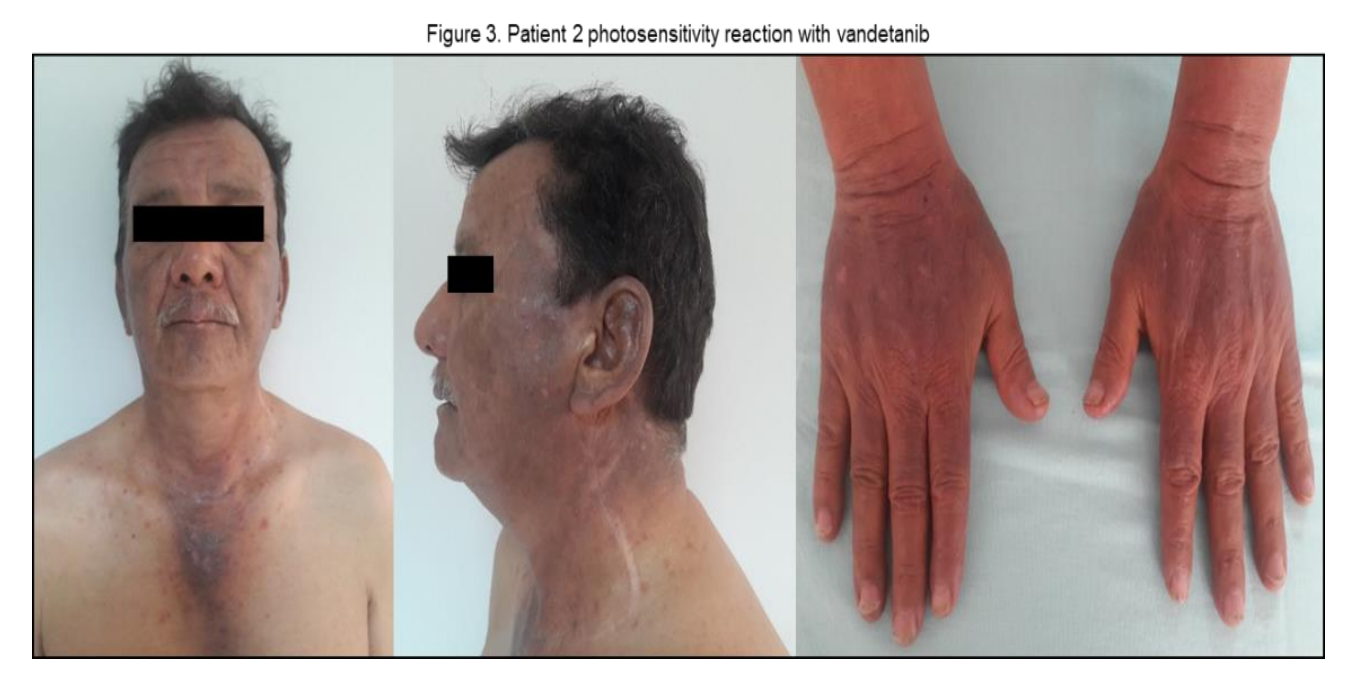

\section{Discussion}

Advanced MTC comprises locally aggressive disease that is not susceptible to surgical resection along with metastatic disease [2,11]. Locoregional involvement is associated with a decrease in 5-year recurrence-free survival, rates of $75 \%$ with localized thyroid disease versus $66 \%$ with regional involvement [12] and decreased overall survival with an increase in the number of lymph nodes involved; the rates of overall survival according to the number of lymph nodes involved (in parentheses) are 76\% (1-5), 74\% (6-10), 61\% (11-15), and 69\% ( $\geq$ 16) [13]. All our patients had regional lymph node involvement, which was evident at diagnosis in three patients.

Metastatic disease can be detected at diagnosis in $4-17 \%$ of the patients and during follow-up in 18-38\% of them. The metastases usually affect the liver (67-69\%), lung (54-60\%), and bone (34-51.1\%) and less frequently the brain, breast, and soft tissues [2]. The most frequent metastatic sites in our patients were the lungs in 5 patients and liver in 4 patients, and in all except one patient (patient 5), the metastases were detected during follow-up. In contrast to higher rates of bone metastases described in the literature, only one patient in our study presented bone involvement. One patient had metastases to the breast, which are rare, as mentioned above. Metastatic disease can be asymptomatic or may present with symptoms related to local involvement or increased hormonal production (diarrhea, flushing, and less frequently, ACTH-dependent Cushing's syndrome) [2]. Two patients in this case series presented calcitonin-associated diarrhea and did not respond to management with TKI.
The objectives of treatment in locally aggressive MTC are pain control, prevention of upper airway involvement, maintenance of phonation and swallowing, and preservation of parathyroid function and shoulder mobility [1]. In these cases, the decision to perform a surgical procedure must be based on the impact of the disease on vital structures (airway and/or digestive tract), with the objective of preserving the functionality of these organs and reducing complications $[1,14]$. This was the case in Patient 1, who had a mediastinal mass resected due to compression of cranial nerves IX and X, and in Patient 2, in whom there was a risk of vascular compression.

Pulmonary metastases are often micronodular and multiple [1,2]. None of our patients received local therapy due to metastatic pulmonary involvement. Hepatic metastases are generally multiple; thus, surgery is not feasible in most cases. In Patient 3, metastasectomy was performed taking into account a very localized metastatic disease, but the patient developed progression 1 year after the procedure. Local therapies such as ablation, transarterial embolization or chemoembolization, may be useful in selected cases [1], as in Patient 4, who underwent intra-arterial embolization to decrease the secretory burden of the tumor and achieved disease control for 4 years. Among bone metastases, the most frequent ones are to the spine $(92 \%)$, pelvis $(69 \%)$, and ribs (53\%) [15]. Bone metastases may be managed with surgery, radiofrequency ablation, or radiotherapy [2]. Antiresorptive agents, like bisphosphonates or denosumab, improve pain and have an impact on decreasing the emergence of related skeletal events [15]. Radiotherapy of the neck and/or mediastinum allows for local control of the tumor in cases with a high probability of recurrence or when surgical excision cannot be performed or is incomplete, improving relapse-free survival but with no 
impact on overall survival $[1,16]$. Patient 2 received mediastinal radiotherapy due to a risk of compression of vital structures 5 years after initial mediastinal resection and had an adequate response for 5 years, when TKI was then recommended.

Systemic therapy such as TKIs or chemotherapy, has a positive impact on progression-free survival (PFS) in patients with MTC and has been associated with partial response or stable disease. This type of therapy should be considered in case of progression and high tumor burden [11,17], but is not recommended in patients with detectable calcitonin without imaging-confirmed metastasis, non-measurable disease (less than $1 \mathrm{~cm}$ ), or in cases of stable or slow-progressive disease [2,17].

TKIs are used in advanced MTC considering the association of the disease with germline and somatic activating mutations of the RET gene and overexpression of vascular endothelial growth factor receptor (VEGFR) 1-2-3, vascular endothelial growth factor (VEGF)-A, fibroblast growth factor receptor 4 (FGFR-4), platelet-derived growth factor receptor (PDGFR), epidermal growth factor receptor (EGFR), and hepatocyte growth factor (HGF) [18]. While TKIs may decrease calcitonin levels, the decrease not always correlate with a reduction in tumor size. In our patients, the biochemical response was irregular despite an adequate structural response. Currently, the only TKIs that have demonstrated longer PFS and reduction in pain and in symptoms of increased hormonal secretion in randomized, placebo-controlled clinical trials and which are approved by the FDA for treatment of advanced MTC are vandetanib (2011) and cabozantinib (2012) [1]. Vandetanib is a multikinase inhibitor with effects on RET, VEGFR-2, VEGFR-3, and EGFR [18,19]. The effectiveness and safety of vandetanib have been demonstrated in two phase 2 studies of hereditary MTC [20,21]. Robinson et al. [20] reported partial response in $16 \%$ and stable disease in $53 \%$ of their patients for 24 weeks using a vandetanib dose of $100 \mathrm{mg} / \mathrm{day}$. Wells et al. [21], using a vandetanib dose of $300 \mathrm{mg} /$ day in 30 patients with advanced MTC, reported partial response (PR) in $20 \%$ and stable disease (SD) in $53 \%$ of the cases, with a median PFS of 27.9 months $(95 \%$ confidence interval [CI] 19.4-not reached). The ZETA study [22] was a phase 3, multicenter, randomized, double-blind, placebo-controlled, cross-over trial of vandetanib $300 \mathrm{mg} /$ day in 331 patients with hereditary and sporadic advanced MTC with stable or progressive disease. The PFS was statistically significant (hazard ratio [HR] 0.46; 95\% CI $0.31-0.69 ; p<$ 0.01 ) and was estimated at 30.5 months compared with 19.3 months with placebo. Partial response was $44 \%$ with vandetanib, and the mean duration of response was 22 months. Ramos et al. [23], analyzed the response to vandetanib in 21 patients with use over 48 months (longterm), finding a complete response $3 / 21(14.3 \%)$, PR in $15 / 21(71.4 \%)$, SD in $3 / 21(14 \%)$ and mean PFS of $73.2 \%$ months. Kim et al. [24], in a recent cohort study of 12 patients with advanced MTC, found five (42\%) and seven $(58 \%)$ patients with PR and SD, respectively. The estimated of DCR was $83 \%$.

The indication for vandetanib treatment in our patients was disease progression, and the medication obtained DCR in 4 of our 5 patients, 1 patient with partial response and 3 with stable disease. One patient developed progression after 12 months of stable response. In subgroup analyses, response with vandetanib has been demonstrated regardless of the presence of RET mutation, metastasis location, or baseline tumor burden. A post hoc analysis of the ZETA study in patients with progression and symptoms, 127 patients treated with vandetanib versus 57 treated with placebo, reported a median PFS of 21.43 months (HR 0.43; 95\% CI, 0.28-0.64; $p<0.0001$ ) and objective response of $43.7 \%$ [25]. No statistically significant differences were found in the subgroup of progression without symptoms. The mean treatment duration in our patients was 16.5 months (6 to 27 months), which was lower than the corresponding mean duration in the ZETA trial
(22 months), although in the ZETA trial, treatment extended until disease progression or study withdrawal. The longest follow-up duration was in patient 2 (27 months), who had stable disease at the moment of data collection for the present study.

In the ZETA trial, the most common AEs were diarrhea (56\%), rash $(45 \%)$, nausea $(33 \%)$, hypertension $(32 \%)$, headache $(26 \%)$, and fatigue (24\%). A QT interval prolongation of $35 \mathrm{~ms}$ compared with baseline was observed in $90 \%$ of the participants, while a prolongation of $60 \mathrm{~ms}$ was observed in $36 \%$ of them [22]. In our study, one of the patients presented grade 1 QT prolongation, with a maximum increase of $44 \mathrm{~ms}$ and normalization after reduction of the vandetanib dose to $200 \mathrm{mg} /$ day.

The most common causes of grade 3 or greater toxicity were diarrhea (11\%), hypertension (9\%), and QT prolongation (8\%) [22]. Grade 3 AEs in our series occurred in 3 patients (diarrhea, hypertension, and rash).

While the recommended dose of vandetanib is $300 \mathrm{mg} /$ day, 3 of our patients required a dose reduction to $200 \mathrm{mg}$ /day due to side effects, which did not affect their treatment response. Data are limited in terms of the efficacy of vandetanib $100 \mathrm{mg}$ [20]. A phase 4 study is underway comparing vandetanib $150 \mathrm{mg}$ versus $300 \mathrm{mg}$ in patients with advanced progressive or symptomatic MTC [26].

Cabozantinib inhibits c-MET, VEGFR-2, RET, AXL, FLT-3, and Tie-2, and its effectiveness in MTC was demonstrated in the EXAM study [27], a multicenter, randomized, placebo-controlled phase 3 trial of cabozantinib $140 \mathrm{mg}$ day that included 330 patients with advanced progressive MTC (previous 14 months). The median PFS with cabozantinib was 11.2 months compared with 4 months in the placebo group (HR $0.28 ; 95 \%$ CI $0.19-0.4 ; p<0.0001$ ). Partial response was $28 \%$, and the estimated response duration was 14.6 months. The most frequent causes of grade 3 or greater toxicity were diarrhea $(16 \%)$, palmoplantar erythrodysesthesia (12.6\%), and fatigue (9.3\%). Other AEs were hypertension, bleeding, fistula formation, and gastrointestinal perforation. This medication is not approved in Colombia to MTC.

The EXAM trial [27] (cabozantinib) included only patients with progressive MTC, as opposed to the ZETA trial (vandetanib), which included patients with progressive and stable disease. This could explain why PFS was greater in the ZETA trial compared with the EXAM trial. None of these studies demonstrated impact of both these TKIs on overall survival; this was possibly related to the slow progression of advanced MTC, which hindered the evaluation of overall survival in the described studies. There are no studies directly comparing cabozantinib with vandetanib, in a real world study of forty-eight patients of which 25 patients received vandetanib as first-line treatment. The PR, SD $\geq 24$ weeks and PD in patients taking vandetanib was 26\%, 34\% and $21 \%$ respectively compared to the $\mathrm{PR}, \mathrm{SD} \geq 24$ weeks and $\mathrm{PD}$ in patients taking cabozantinib of $22 \%, 13 \%$ and $35 \%$ respectively. Median PFS from vandetanib was 17 months and cabozantinib was 4 months. The lower response rates of cabozantinib treated patients is likely due that was mainly used as a second-line treatment after PD on vandetanib. Both TKIs demonstrted similar efficacy in second-line setting (PR around 30\% of patients) [28].

Phase 2 studies have found a positive impact of sunitinib 27 and sorafenib 28 in patients with MTC who progressed with vandetanib or cabozantinib, demonstrating rates of partial response of $38 \%$ and stable disease of $35 \%$ with sunitinib. With sorafenib, rates of partial response have been described at $6.3 \%$ and stable disease at $87.5 \%$. Phase 2 studies have also used lenvatinib [29][30] and everolimus [31], but none of these medications has yet been approved for treatment of MTC. Chemotherapeutic agents like dacarbazine, 5-fluorouracil, cisplatin, and doxorubicin, either alone or in combination, have demonstrated partial 
response or stable disease rates ranging from $10-20 \%$, with a short duration of effect [17,32].

\section{Conclusions}

The management of advanced progressive MTC with vandetanib allows for prolonged disease control (stable disease or partial response). While mild AEs are frequent, severe cases resolved without complications after dose adjustment.

\section{Ethical Approval}

The present investigation was carried out in accordance with the Declaration of Helsinki, national norms set forth in resolution 8430 of October 4, 1993, which classify the study as a "risk-free investigation." and were in accordance with the ethical standars of the institutional ethics committee. Informed consent was obtained from the patients for registration and publication of pictures and diagnostic images.

\section{Conflict Of Interest}

The authors declare that there are no conflicts of interest that may affect the impartiality of the reported investigation.

\section{Acknowledgments}

We thank the patients who agreed to participate in the study and who consented to the publication of their pictures and diagnostic images

\section{References}

1. Wells SA, Asa SL, Dralle H, Elisei R, Evans DB, Gagel RF, et al. (2015) Revised American thyroid association guidelines for the management of medullary thyroid carcinoma. Thyroid.25(6):567610.

2. Hadoux J, Pacini F, Tuttle RM, Schlumberger M. (2016) Management of advanced medullary thyroid cancer. Lancet Diabetes Endocrinol [Internet].4(1):64-71.

3. Donis-keller H, Dou S, Chi D, Carlson KM, Toshima K, Lairmore TC, et al. (1993) Mutations in the RET proto-oncogene are associated with MEN 2a and FMTC. Hum Mol Genet.2(7):851856.

4. Dvorakova S, Vaclavikova E, Sykorova V, Vcelak J, Novak Z, Duskova J, et al. (2008) Somatic mutations in the RET protooncogene in sporadic medullary thyroid carcinomas. Mol Cell Endocrinol.284(1-2):21-27.

5. Boichard A, Croux L, Al Ghuzlan A, Broutin S, Dupuy C, Leboulleux S, et al. (2012) Somatic RAS mutations occur in a large proportion of sporadic RET-negative medullary thyroid carcinomas and extend to a previously unidentified exon. J Clin Endocrinol Metab.97(10):1-5.

6. Moura MM, Cavaco BM, Pinto AE, Leite V. (2011) High prevalence of RAS mutations in RET-negative sporadic medullary thyroid carcinomas. J Clin Endocrinol Metab.96(5):863-868.

7. Roman S, Lin R, Sosa JA. (2006) Prognosis of medullary thyroid carcinoma: Demographic, clinical, and pathologic predictors of survival in 1252 cases. Cancer.107(9):2134-2142.

8. Eisenhauer EA, Therasse P, Bogaerts J, Schwartz LH, Sargent D, Ford R, et al. (2009) New response evaluation criteria in solid tumours: Revised RECIST guideline (version 1.1). Eur J Cancer [Internet].45(2):228-247.

9. Cancer Therapy Evaluation Program (CTEP). (2017) Common Terminology Criteria for Adverse Events (CTCAE).v.5.0 [5x7]. Cancer Ther Eval Progr [Internet].155.

10. Chiladakis J, Kalogeropoulos A, Arvanitis P, Koutsogiannis N, Zagli F, Alexopoulos D. (2010) Preferred QT correction formula for the assessment of drug-induced QT interval prolongation. J Cardiovasc Electrophysiol.21(8):905-913.
11. Ernani V, Kumar M, Chen AY, Owonikoko TK. (2016) Systemic treatment and management approaches for medullary thyroid cancer. Cancer Treat Rev [Internet].50:89-98.

12. Geller G, Laskin J, Cheung WY, Ho C. (2017) A retrospective review of the multidisciplinary management of medullary thyroid cancer: Eligibility for systemic therapy. Thyroid Res. 10(1):4-9.

13. Esfandiari NH, Hughes DT, Yin H, Banerjee M, Haymart MR. (2014) The effect of extent of surgery and number of lymph node metastases on overall survival in patients with medullary thyroid cancer. J Clin Endocrinol Metab.99(2):448-454.

14. Konstantinidis A, Stang M, Roman SA, Sosa JA. (2017) Surgical management of medullary thyroid carcinoma. Updates Surg. 69(2):151-160.

15. Xu JY, Murphy WA, Milton DR, Jimenez C, Rao SN, Habra MA, et al. (2016) Bone metastases and skeletal-related events in medullary thyroid carcinoma. J Clin Endocrinol Metab. 101(12):4871-4877.

16. Mangoni M, Gobitti C, Autorino R, Cerizza L, Furlan C, Mazzarotto R, et al. (2017) External beam radiotherapy in thyroid carcinoma: Clinical review and recommendations of the AIRO "Radioterapia Metabolica" Group. Tumori.103(2):114-123.

17. Hadoux J, Schlumberger M. (2017) Chemotherapy and tyrosinekinase inhibitors for medullary thyroid cancer. Best Pract Res Clin Endocrinol Metab [Internet]. 31(3):335-347.

18. Rajabi S, Hedayati M. (2017) Medullary Thyroid Cancer: Clinical Characteristics and New Insights into Therapeutic Strategies Targeting Tyrosine Kinases. Mol Diagnosis Ther. 21(6):607-620.

19. Vitagliano D, De Falco V, Tamburrino A, Coluzzi S, Troncone G, Chiappetta G, et al. (2011) The tyrosine kinase inhibitor ZD6474 blocks proliferation of RET mutant medullary thyroid carcinoma cells. Endocr Relat Cancer. 18(1):1-11.

20. Robinson BG, Paz-Ares L, Krebs A, Vasselli J, Haddad R. (2010) Vandetanib $(100 \mathrm{mg})$ in patients with locally advanced or metastatic hereditary medullary thyroid cancer. J Clin Endocrinol Metab. 95(6):2664-2671.

21. Wells SA, Gosnell JE, Gagel RF, Moley J, Pfister D, Sosa JA, et al. (2010) Vandetanib for the treatment of patients with locally advanced or metastatic hereditary medullary thyroid cancer. J Clin Oncol. 28(5):767-772.

22. Wells SA, Robinson BG, Gagel RF, Dralle H, Fagin JA, Santoro M, et al. (2012) Vandetanib in patients with locally advanced or metastatic medullary thyroid cancer: A randomized, double-blind phase III trial. J Clin Oncol. 30(2):134-141.

23. Ramos HE, Hecht F, Berdelou A, Borget I, Leboulleux S, Baudin E, et al. (2020) Long-term follow-up and safety of vandetanib for advanced medullary thyroid cancer. Endocrine [Internet].

24. Kim M, Yoon JH, Ahn J, Jeon MJ, Kim HK, Lim DJ, et al. (2020) Vandetanib for the Management of Advanced Medullary Thyroid Cancer: A Real-World Multicenter Experience. Endocrinol Metab. 35(3):587-594.

25. Kreissl MC, Bastholt L, Elisei R, Haddad R, Hauch O, Jarzab B, et al. (2020) Efficacy and safety of vandetanib in progressive and symptomatic medullary thyroid Cancer: Post hoc analysis from the ZETA trial. J Clin Oncol. 38(24):2773-2781.

26. To Compare The Effects Of Two Doses Of Vandetanib In Patients With Advanced Medullary Thyroid Cancer [Internet]. Clinical trials.gov. Report No.: NCT01496313.

27. Elisei R, Schlumberger MJ, Müller SP, Schöffski P, Brose MS, Shah MH, et al. (2013) Cabozantinib in progressive medullary thyroid cancer. J Clin Oncol. 31(29):3639-3646.

28. Koehler VF, Adam P, Frank-Raue K, Raue F, Berg E, Hoster E, et al. (2020) Real-World Efficacy and Safety of Cabozantinib and Vandetanib in Advanced Medullary Thyroid Cancer. Thyroid. 133. 
29. Liu X, Shen T, Mooers BHM, Hilberg F, Wu J. (2018) Drug resistance profiles of mutations in the RET kinase domain. Br J Pharmacol. 175(17):3504-3515.

30. Schlumberger M, Jarzab B, Cabanillas ME, Robinson B, Pacini F, Ball DW, et al. (2016) A phase II trial of the multitargeted tyrosine kinase inhibitor lenvatinib (E7080) in advanced medullary thyroid cancer. Clin Cancer Res. 22(1):44-53.

31. Lim SM, Chang H, Yoon MJ, Hong YK, Kim H, Chung WY, et al. (2013) A multicenter, phase II trial of everolimus in locally advanced or metastatic thyroid cancer of all histologic subtypes. Ann Oncol. 24(12):3089-3093.

32. Marchand L, Nozières C, Walter T, Descotes F, DecaussinPetrucci M, Joly MO, et al. (2016) Combination chemotherapy with 5-fluorouracil and dacarbazine in advanced medullary thyroid cancer, a possible alternative? Acta Oncol (Madr). 55(8):1064-1066. 